\title{
A policy development perspective on drinking water policy
}

\author{
James O. Jenkins \\ School of Life Sciences \\ University of Hertfordshire \\ College Lane \\ Hatfield, Hertfordshire, AL10 9AB, UK \\ E-Mail: j.o.jenkins@herts.ac.uk
}

\begin{abstract}
This paper seeks to address the lack of knowledge in the water industry of how policy development can be understood to have shaped the development and application of European Union (EU) drinking water policy. In particular, the paper develops a comparative understanding of how policy development can be viewed as having affected the development and application of the Drinking Water Directive (80/778/EEC) in England/Wales and the Republic of Ireland. As a result of this focus, the paper explores policy development issues relating to conflicting interests, invalid causal theories, political symbolism, lack of attention to detail by policy makers, and the allocation of duties and resources. It is subsequently established that consideration of these issues is useful in fostering a focused understanding of how policy development may have affected policy application. Despite the significant changes which took place with regard to the development of the current Drinking Water Directive (98/883/EC), the paper concludes by arguing that greater attention should be accorded the conflicting interests and abilities of Member States during the development of EU water policy, particularly if attempts are to be made to identify
\end{abstract}


Final draft of paper accepted for publication in the Journal 'Water Policy'. Actual journal publication should be referenced.

measures targeted at improving the application of EU water policy in a diverse political and economic union of member states.

Key words | Directive 80/778/EEC; drinking water; England/Wales; Ireland; policy application; policy development

\section{INTRODUCTION}

Accepting that polices are rarely made in a rational manner does not prevent the researcher from wanting to explore how policy is developed and how this affects policy application (Winter, 2003; Carter, 2007). Research focusing on the application of public policy has shown that resultant policy failures and problems are attributable to the conflicting interests of policy-makers. While such an acceptance is useful it offers a somewhat blinkered view of the consequences of policy development. In addition to conflicting interests, Winter (2003) suggests that invalid causal theories, political symbolism, lack of attention to detail by policy makers, and allocation of resources, are all important issues to consider when seeking to better understand how policy development may affect policy application. Therefore, this paper argues that exploration of the aforementioned issues offers a means by which to gain insights into the developmental stage of European Union drinking water policy and how this stage has in turn affected the application of such policy.

To explore the impact of policy development on application, this paper is split into three main sections. The first section provides an overview of the Drinking Water Directive 80/778/EEC and its application. This second section provides a brief 
Final draft of paper accepted for publication in the Journal 'Water Policy'. Actual journal publication should be referenced.

overview of the methodological approach used to undertake the study, whilst the third section focuses on exploring issues of conflicting interests, invalid causal theories, political symbolism, lack of attention to detail by policy-makers, and the allocation of duties and resources, to glean insights into how policy development may have influenced the application of Directive 80/778/EEC in England and Wales and in the Republic of Ireland ${ }^{1}$.

\section{THE DRINKING WATER DIRECTIVE}

The Drinking Water Directive (80/778/EEC), adopted on the $15^{\text {th }}$ July 1980 , established, for the first time, EU-wide parametric standards for water intended for human consumption. Prior to the Directive, Member States had set their own national standards. The Directive was developed and subsequently adopted by Member States in an attempt to standardise drinking water quality parameters across the EU (CEC, 1980; NSCA, 2000; Collins, 1988; Haigh, 1998).

Directive $80 / 778 /$ EEC was plagued by delays and misinterpretations that served to affect its adoption and subsequent enforcement. In particular, Member States were meant to have implemented the Directive by 1982 (CEC, 1980). However, a report produced by Ken Collins, former Chair of the European Parliament Environment Committee, commented that:

'Not a single Member State had communicated to the Commission the legislative, regulatory or administrative measures taken to comply with

\footnotetext{
${ }^{1}$ For conciseness, from this point onwards, England and Wales are referred to as England/Wales, whilst the Republic of Ireland is referred to as Ireland.
} 
Final draft of paper accepted for publication in the Journal 'Water Policy'. Actual journal publication should be referenced.

the directive by the end of the two-year period allowed for the directive's transposition in national law' (Collins, 1988: 29).

Collins highlights that by 1987 , the Commission had initiated legal proceedings against Belgium, France, Germany and Ireland for failure to implement the Directive. As Table 1 demonstrates, by 1998 it appears that all Member States affected by the Directive had put in place measures to ensure correct legal transposition. However, 1985 was to mark the year Member States were meant to be compliant with the Directive but, as Table 1 indicates, in 1998 no Member State was compliant with the parameters detailed in the Directive. As Table 2 illustrates, Member States appeared to be exhibiting failure across a selection of the Directive's parameters. Furthermore, Table 3 not only draws attention to the problem parameters and rates of noncompliance in Member States but also draws attention to the differing approaches used to ensure compliance with the Directive. This is evidenced by the varying availability of national drinking water reports. Indeed, when Table 3 is studied further, varying approaches to compliance sampling are evident. For example, some Member States (e.g. Belgium and Germany) chose not to report on certain standards, either deliberately or because they were insufficiently monitoring to ensure compliance with the Directive.

\section{METHODOLOGICAL BACKGROUND}

The research from which this paper has been extracted adopted a qualitative approach to the analysis of the application of Directive 80/778/EEC in England/Wales and Ireland. Data was collected from a series of semi-structured interviews conducted in 
Final draft of paper accepted for publication in the Journal 'Water Policy'. Actual journal publication should be referenced.

England/Wales, Ireland and Brussels. The semi-structured interview approach allowed a series of predetermined questions to be developed, which could then be expanded upon during the interview if an interesting comment needed further exploration. Interviewees were initially selected from interviewee articles in professional publications, related academic research literature, and direct liaison with current individuals involved in the provision of water services. The interviewee base was then expanded via a process of snowballing ${ }^{2}$.

All interviews were conducted under an umbrella of confidentiality and were subsequently made anonymous. Interviewees were selected to represent the organisations and individuals involved in the application of Directive 80/778/EEC. In Ireland, a total of 19 interviews were undertaken with individuals from the Department of the Environment and Local Government (DOELG) and the Environmental Protection Agency (EPA). Individuals from the providers of water services were also selected for interview, which included Dublin City Council, Fingal County Council, Rathdown County Council, and South Dublin City Council. In England/Wales, a total of 33 interviews were undertaken with individuals from the Department for Environment, Food and Rural Affairs, the Office of Water Services (Ofwat), the Drinking Water Inspectorate (DWI), and WaterVoice. Representatives of the providers of water services in the London area, namely Thames Water and Three Valleys Water, in addition to individuals from national representative groups such as Water UK, were also selected for interview. At the EU level a total of 12 individuals

\footnotetext{
${ }^{2}$ This process involved asking interviewees for recommendations of who could be interviewed next.
} 
Final draft of paper accepted for publication in the Journal 'Water Policy'. Actual journal publication should be referenced.

were interviewed, being drawn from the EC and the European Parliament (EP). Individuals were also selected for interview from the European Union of National Associations of Water Suppliers and Waste Water Services (Eureau). All interviews, with the exception of one, were conducted in person, with the length of interviews ranging from 30 minutes to over 2 hours.

Where possible, interviewees were selected to help generate a contemporary understanding of the application of Directive 80/778/EEC between 1975 and 2002. This was undertaken to ensure that the initial policy development process and changes in application practice could be analysed over time. The information collected was supplemented with information derived from reports and papers from parliamentary committees and proceedings, government departments, EU organisations and institutions, privately commissioned research, interviewee articles and conference presentations. The Times and Irish Times were also consulted to aid in the construction of a contemporary picture of policy application.

\section{POLICY DEVELOPMENT AND DIRECTIVE 80/778/EEC}

To allow insights into how the policy development stage affected policy application, the following discussion is split into five sub-sections that seek to explore the impact of conflicting interests, invalid causal theories, political symbolism, poor attention by policy-makers, and the allocation of duties and resources to the application of the Drinking Water Directive 80/778/EEC in England/Wales and Ireland.

\section{Conflicting interests and the Directive}


Final draft of paper accepted for publication in the Journal 'Water Policy'. Actual journal publication should be referenced.

Member States unanimously adopted Directive 80/778/EEC on $15^{\text {th }}$ July 1980 (CEC, 1980). However, it is important to note that at the time of adoption, the text of environmental directives had to be agreed upon unanimously (Cini, 2007). Therefore, such unanimity should not be taken as implying that the Directive was adopted without Member States entering into a process of bargaining and negotiation that sought to resolve conflicting interests with regard to the regulation of drinking water. Indeed, the Directive was adopted following five years of negotiations and over 50 meetings (see CEC, 1975; CEC, 1980).

It is notable that England/Wales and Ireland entered into a bargaining process in a desire to protect themselves from legislation that was felt to be creating a water quality 'problem' with regard to the concentration of lead in drinking water. For example, the comments of a former senior scientist of the Water Research Centre (WRc) in England/Wales serve to highlight the desire of civil servants to achieve flexibility on how the lead standard of the Directive would be applied:

'When the Drinking Water Directive was being drafted, the Department of the Environment facilitated the undertaking of a survey on lead in drinking water...the results were thought to be quite shocking by those involved in the negotiations...the UK subsequently lobbied hard in this area for a more sympathetic sampling regime' (Senior Scientist WRc [England/Wales], per. comm.).

It was subsequently argued by the same interviewee that this resulted in Directive 80/778/EEC being worded loosely to allow Member States flexibility in applying the Directive: 
Final draft of paper accepted for publication in the Journal 'Water Policy'. Actual journal publication should be referenced.

'The Drinking Water Directive was in the end worded loosely, it would have been stupid to clobber ourselves with legislation that was too strict...well, that was very much the attitude of those involved in the negotiations' (Senior Scientist WRc [England/Wales], per. comm.).

According to Winter (2003), a key consequence of policy negotiations, and the bargaining that ensues, is that it discourages clear definition of policy goals and the use of vague terminology. Why vague terminology may result as a consequence of policy negotiations is commented upon in detail by a House of Lords Committee on the European Community (HOLSEC) report on the application of EU environmental legislation in the UK. In particular, the report suggests that vagueness occurs in the context of EU policy because of the differing political and economic impacts legislation has on Member States, and the subsequent discretion it allows in a nation state response:

'if there are major differences in the political or economic impacts of a specific piece of legislation on Member States, vagueness may well be essential for reaching harmonisation...vagueness allows for a degree of desirable national discretion and hence for factors such as differences in capacity and perception' (HOLSEC, 1992: 11)

Indeed, the text of Directive $80 / 778 / \mathrm{EEC}$ is littered with vague terminology. For example, in relation to monitoring, the Directive is vague about how often and with which methods drinking water should be tested for compliance with the standards of the Directive, and which factors may have a negative impact on the quality of 
Final draft of paper accepted for publication in the Journal 'Water Policy'. Actual journal publication should be referenced.

drinking water. The following excerpts from the Directive clearly illustrate these examples of vagueness:

'Member States shall take all necessary steps to ensure regular monitoring of the quality of water intended for human consumption' (CEC, 1980: 13).

'The competent national authorities of the Member States will determine the parameters according to circumstances, taking account of all factors which might have an adverse affect on the quality of drinking water supplied to consumers' (CEC, 1980: 24).

The vagueness of phrases and terms such as 'all necessary steps' and 'determine the parameters according to circumstances' have allowed England/Wales and Ireland considerable flexibility in interpretation. More specifically, the Departments of the Environment in England/Wales and Ireland chose to interpret the 'Maximum Admissible Concentrations' (MACs) ${ }^{3}$ specified by Directive as annual averages. For example, in 1982 the DoE in England/Wales stated that MACs were:

'The maxima to which average concentrations may rise without an expectation of ill effect in the population in general' (Circular 20/82 DoE [England/Wales]: 3).

The Irish Department of the Environment similarly stated that:

\footnotetext{
${ }^{3}$ MACs indicate the concentration beyond which a certain substance, specified in Directive 80/778/EEC, is not allowed to occur in any given sample.
} 
Final draft of paper accepted for publication in the Journal 'Water Policy'. Actual journal publication should be referenced.

'An average value from routine samples, taken from a water supply system as a whole, over a period of time, does not breach the prescribed value' (Circular L.6/83 DOELG [Ireland]: 6, emphasis in original document).

Although the Directive does not give any guidance on the interpretation of MAC values (see CEC, 1980), subsequent action by the Environment Commission forced Member States to change their stance. This clarification of how MAC values should be interpreted is indicated clearly by the Irish Department of the Environment in a circular accompanying the European Communities (Quality of Water Intended for Human Consumption) Regulations, 1988:

'The Commission has indicated that there is no basis in the Directive for the advice about averaging values given to sanitary authorities in 1983 and that the Directive prohibits any value above a maximum admissible concentration...The Department has raised the practical operational aspects of this requirement with the Commission, however, pending further developments, the advice given in 1983 on this matter is now withdrawn, and to comply with the Regulations it will be necessary to show that the result from each sample do not breach the prescribed standards’ (Circular L6/88 DOELG [Ireland]: 2).

As a result of this 'misinterpretation', England/Wales and Ireland were not compliant with the standards of the Directive, indeed their stance towards MAC values had led them to believe they would be fine, as the comments of a former water company chairman in England/Wales typify: 
Final draft of paper accepted for publication in the Journal 'Water Policy'. Actual journal publication should be referenced.

'The industry felt that it would be fine and would be able to comply with few problems, especially as the standards were thought to be applicable in annual means, which led one to believe that such substances as Nitrate would not be a problem' (Former Chairman of Water Company [England/Wales], per. comm.).

This view is further supported by a former senior executive of Thames Water who, in reference to MAC values, stated:

'The Drinking Water Directive Nitrate parameter took Thames by
surprise. Originally we thought we would comply with the upper limit and
get away with it' (Senior Executive Thames Water [England/Wales], per.
comm.).

The argument that there was a need for Member States policy-makers to compromise during policy negotiations and thus appease conflicting interests is supported by the work of Haigh (1998). In particular, he has commented that the need for unanimity in adopting the Directive resulted in the text of the Directive being littered with examples of vague terminology. Therefore, the vagueness of the Directive's text serves to shed light on why England/Wales and Ireland exhibited problems and delays in the application of the Directive, as it permitted incorrect national responses to the application of the Directive to take hold.

\section{Causal theory and the Directive}


Final draft of paper accepted for publication in the Journal 'Water Policy'. Actual journal publication should be referenced.

Directive 80/778/EEC has been alleged to be 'technically deficient' in certain areas, most notably with regard to quality standards it set for pesticides. In particular, the now defunct Water Authorities Association of England/Wales remarked in 1987 that: 'the Directive has had a beneficial effect in focusing attention on the quality of drinking water. Water quality experts across Europe agree with the aims of the Directive but it is a complex document and many feel that it has a number of technical deficiencies. These have led to differences in interpretation and implementation between different Member States and hence the well publicised action by the Environment Commission' (WAA, 1987: 2).

In reference to particular deficiencies of Directive 80/778/EEC, a former Director of Quality and Environmental Services of Severn Trent Water commented that: 'One of the major deficiencies of the Directive is that it gives no scientific justification for any one of the standards. This is in contrast to WHO guidelines where the evidence on which the guideline values are set is fully documented. By present-day knowledge, the MACs for a number of parameters are highly dubious. For example there seems little justification for the EC nitrate standard which is not even included in WHO guidelines. Similarly it is clear that a single pesticide standard of $0.1 \mu \mathrm{g} / \mathrm{l}$ is toxicologically indefensible for the wide range of individual compounds which it covers' (Breach, 1989: 326).

This approach to the regulation of pesticides in drinking water has been cited by some within the water industry as being irrational and unscientific. In particular, 
Final draft of paper accepted for publication in the Journal 'Water Policy'. Actual journal publication should be referenced.

interviewees highlighted that the total limit standard of $0.5 \mu \mathrm{g} / \mathrm{l}$, and the blanket $0.1 \mu \mathrm{g} / 1$ for individual pesticides were scientifically flawed because they take no account of the fact that certain pesticides can occur at higher levels without impacting upon human health:

'The standards adopted for the pesticides parameter were stupid, not all pesticides are the same' (Senior Representative WAA, per. comm.).

'Some of the parameters in the Directive are not scientific, for example pesticides. The values adopted are too severe...the standard could be higher and still be able to protect public health' (Senior DWI II, per. comm.).

'The main problems of the Directive are that some of the standards are unscientific' The core celebrity in this case is the pesticide standard which owes more to limits of detection than public health impacts' (Senior Ofwat Representative, per. comm.).

It was subsequently suggested by some interviewees that the standards set for pesticides owed more to the limits of detection and a desire to push such sampling limits than to any specific scientific rationale:

'Many of the standards included in the Directive were technology driven, if you could measure them then there was an attitude of "lets include them"...this was certainly not scientific' (Senior Civil Servant II DoE [England/Wales], per. comm.). 
Final draft of paper accepted for publication in the Journal 'Water Policy'. Actual journal publication should be referenced.

'Some of the sampling limits in the Directive were based on the sampling limits of the time, they were in effect surrogate zeros that did not have any epidemiological founding, pesticides is a notable example' (Senior Engineer Fingal County Council [Ireland], per. comm.).

'The vast majority of standards in the Directive are scientific but notable exceptions are pesticides and solvents. The $0.1 \mu \mathrm{g} / \mathrm{l}$ limit for indivividual pesticides is the equivalent of a surrogate zero, it was the detection limit at the time of negotiations' (Eureau Drinking Water Representative, per. comm.).

Concerns surrounding the scientific integrity of the Directives' standards did not only emerge during the Directive's application in Members State, and should not be taken as being a sign of disgruntlement because Members States, like England/Wales and Ireland, were struggling to meet the standards laid down by the Directive. For example, the 1976 Economic and Social Committee report on the draft version of the Directive is notable because it expressed concerns about the scientific validity of the Directive's standards at the time of its development:

'...in many instances the standards are much stricter and the Section [Committee] wonders what justification there is for this [...] there is no indication of how they relate to the existing standards in the Member States' (ESC, 1976: 6). 
Final draft of paper accepted for publication in the Journal 'Water Policy'. Actual journal publication should be referenced.

Why a more scientific argument for standards did not prevail is arguably due to the apparently negative impact of politics, as the following interviewee comment suggests:

'It was wrong for the Directive to have been drafted with political people being involved. The wrong approach was adopted and trade offs were made which weren't to the benefit of the Directive. There should have been more technical input...Brussels did not have a clue on how to go about preparing a drinking water directive' (Senior Scientist WRc [England/Wales], per. comm.).

In relation to the accusation that there should have been more technical input, support is forthcoming from the recorded comments of Lord Bethell, the then European Parliament's rapporteur for the Directive. At the time of the Directive's development he drew attention to the environment committee's poor understanding of the science involved in establishing the standards of the Directive:

'I would mention in passing that the Commission's document is a little difficult for parliamentarians to get a total grip of: as in so many of these documents, we find ourselves in committee blinded by science; and not entirely equipped for getting to grips with what are quite complicated chemical matters. We can of course take advice from experts, but this is not always easy to do and we have not been able to go into the real details of the chemical problems of this proposal' (CEC, 1976: 171).

The accusation that some of the standards contained in the Directive were less than scientific, and were based upon incomplete knowledge and the actions of politicians 
Final draft of paper accepted for publication in the Journal 'Water Policy'. Actual journal publication should be referenced.

and thus invalid causal theories, is further substantiated by a series of articles that appeared in the Times Newspaper in England/Wales during the early 1990s. In particular, the scientific basis of the standards set by the Directive began to be questioned due to emerging and increasing concerns relating to how much the consumer would be willing, or able, to pay for the treatment processes necessary to remove pesticides to the standards set by the Directive:

'The EC standards, particularly on eliminating pesticide and nitrate traces, demand purity approaching perfection. The pesticide and nitrate standards reflect scientific caution rather than knowledge' (The Times, 14/08/1992).

'The director-general of water services said standards expected by Brussels were "not all scientifically based, and you could say they were politically based". A substantial burden was placed on customers without full costing at an early stage' (The Times, 30/03/1993).

'Mr Byatt [director-general of Ofwat] accused Brussels and environmentalists of setting utopian goals for EC tap and river water standards. Some of Europe's existing and planned obligations offered little or no tangible benefits to customers' health or the environment and were formulated by ideology rather than science, he said' (The Times, 14/07/1993).

The research undertaken in Ireland did not reveal such a vocal debate about the scientific integrity of the Directive's standards, particularly as a result of the costs 
Final draft of paper accepted for publication in the Journal 'Water Policy'. Actual journal publication should be referenced.

involved in complying with Directive's standards. Why such concerns did not also manifest themselves in Ireland may in part be due to the costs of drinking water treatment not being directly borne by the consumers of water services in Ireland, as explained by the comments of a senior Irish civil servant:

'Domestic water users [in Ireland] don't directly pay for water...if they did, there would be a higher level of concern over water quality and the resultant investment. This is probably why there has been a bigger debate in the UK over water quality costs' (Senior Civil Servant II DOELG [Ireland], per. comm.).

The above comment is to some extent supported by the research of Maloney \& Richardson (1995) who suggested that when water services were paid out of general or local taxes in England/Wales, public concern about water services was low, which appears to be the situation in Ireland.

A further area where valid causal theories can be seen to have been absent during the development of the Directive is apparent in the timeline adopted for full compliance with the standards laid down by the Directive. In particular, by July 1985, all signatories were meant to have been fully compliant but, as a manager from Thames Water remarked:

'The five year compliance timeframe was unrealistic...not enough knowledge or understanding of the water supply set-up may have led to this. For example, it took from 1989 until 1998 to deliver a programme for pesticide treatment' (Manager Thames Water, per. comm.). 
Final draft of paper accepted for publication in the Journal 'Water Policy'. Actual journal publication should be referenced.

Support for the above accusation is forthcoming from a 1976 House of Lords report. This report argued, some nine years before full compliance with the Directive was due, that the Directive's deadline for full compliance were 'wholly unrealistic', with many individuals still being supplied with water that failed to meet the standards of the Directive after this deadline (HOLSEC, 1976: 12). Why the Directive adopted an unrealistic compliance deadlines is attributed to those involved in the negotiations possessing incomplete information. For example, in the context of the pesticides standard, it has been argued that negotiators were not aware of the scale of drinking water contamination because sufficient sampling was not taking place, as the following interviewee comments serve to illustrate:

'The UK did think that some of the parameters wouldn't affect them, for example pesticides...The UK didn't try and negotiate against the pesticide standards because they were not perceived to be a problem at the time. This situation probably arose due to the fact that the UK were not testing for such a parameter' (Senior Inspector DWI, per. comm.).

'A big issue with regards to implementation of the Drinking Water Directive was the pesticides standard...the problem was not known about during the negotiations...it took a while to realise pesticides were going to be a problem...this realisation occurred during the mid 1980s...the problem became apparent, as with other problematic parameters as the Directive increased levels of monitoring taking place to demonstrate compliance... which revealed the scale of the problem and the realisation that technologies had to be developed that could adequately treat water 
Final draft of paper accepted for publication in the Journal 'Water Policy'. Actual journal publication should be referenced.

and monitor for new pesticides on such a scale' (Senior Inspector DWI, per. comm.).

'There was a gradual realisation that the Directive's standards were being breached and this began to emerge via increased sampling...the response was not immediate as a response had to be developed over time via the testing of new technology...the approach to the Directive was very much “learn by doing”' (Senior Engineer, Dublin City Council, per. comm.).

While these comments do not support the conclusions of the 1976 HOLSEC report, one is left wondering how much civil servants did know about nitrate and pesticide contamination in England/Wales, and why they signed up to a Directive that was known to have unrealistic compliance deadlines. With respect to this issue, it is apparent that Directive 80/778/EEC was viewed in an 'aspirational' light, by senior government officials in England/Wales and Ireland, with legality being poorly appreciated by government officials in both national contexts. However, as the following section highlights, the Directive was seen by many as being politically symbolic which helps to explain the apparent willingness of policy-makers and politicians to sign-up to an apparently imperfect policy response.

\section{Policy symbolism and the Directive}

At the time of the negotiations surrounding the Directive, England/Wales and Ireland had only recently joined the EU and, as a consequence, there was an apparent desire by politicians, in both cases, to demonstrate progress and a positive attitude towards 
Final draft of paper accepted for publication in the Journal 'Water Policy'. Actual journal publication should be referenced.

the EU by signing up to new legislation. For example, it is notable that Neil Summerton (a former Head of the Water Directorate in the Department of the Environment) has argued that the Directive owed more to the wider political project of the EU rather than concerns about trade in water:

'Drinking Water...is rarely, if ever traded across national boundaries and standards at the tap do not have transboundary implications. The argument that Europeans should enjoy the same standards at the tap wherever they go in Europe owe more to the European political project than to transboundary and single market arguments' (Summerton, 1998: 111).

The following interviewee comments are clearly indicative of the desire of politicians in England/Wales and Ireland for the EU to succeed and for progress to be demonstrated, which were in part due to the perceived monetary benefits membership would bring:

'Member State governments want to demonstrate progress, and progress is often demonstrated by signing up to new legislation. No one wants to be seen not to be progressing' (Senior Civil Servant III DOELG [Ireland], per. comm.).

'The willingness to sign up to the Directive was high. One must remember that the general attitude in Ireland was that it was benefiting from the EU and didn't want to be seen to be rocking the boat and thus upsetting the paymasters by questioning too much' (Senior Civil Servant I DOELG [Ireland], per. comm.). 
Final draft of paper accepted for publication in the Journal 'Water Policy'. Actual journal publication should be referenced.

'The UK may not have voiced its concerns as it had recently joined the EU and wanted it to succeed' (Senior Civil Servant III DoE [England/Wales], per. comm.).

With regard to the factors that drove Member States to resolve their conflicting interests, it is notable that interviewees remarked on the wider political symbolism of the Directive, with adoption being viewed as signifying progress towards the wider European project of closer political ties and economic integration, as the following interviewee remarks substantiate:

'There is always pressure to agree at the Council of Ministers level, which can make it difficult for ministers to reach a truly balanced decision. A Council of Ministers meeting is often held to achieve progress and there is consequently a strong desire to demonstrate this by adopting new legislation. As a result of this pressure compromises are made' (Senior Civil Servant III DoE [England/Wales], per. comm.).

'At the time of the Directive's negotiations there was a great will to get the Directive past with compromises being reached where necessary. There was a desire to demonstrate progress, particularly at the political level' (Senior Civil Servant II DoE [England/Wales], per. comm.).

\section{Policy-makers' attention and the Directive}

With regard to the development of Directive 80/778/EEC, a number of differing issues have been identified as potentially affecting the level of attention policy- 
Final draft of paper accepted for publication in the Journal 'Water Policy'. Actual journal publication should be referenced.

makers may have been able to afford to the development of the Directive. In particular, in Ireland, an interviewee suggested that because of the small size of the civil service, the attention sometimes afforded legislation was limited because of the resultant time pressures:

'One must remember that the pressures on the civil servant are particularly acute in Ireland. The civil service is small in comparison to other countries and therefore it was often the case that civil servants and ministers would have had a wide range of issues to contend with that were perceived as being more pressing than drinking water...consequently an Irish minister would sign up quite happily without thinking about the long term consequences... Often there was an element of struggling to keep up with the raft of new legislation coming from Europe, there was a tendency to be on the back foot' (Senior Civil Servant I DOELG [Ireland], per. comm.).

From the perspective of England/Wales, it was suggested that, at the time of the negotiations surrounding the Directive, civil servants did not appreciate the bargaining process inherent in EU policy making. This subsequently resulted in legislation that was not wholly in agreement with the UK's interests and thus in part explained subsequent problems of application:

'One may have signed up to Directives in the beginning without necessarily appreciating wider bargaining processes that were happening which may have allowed the development of policy that was not necessarily in agreement with states' interests, or as much as it could have been' (Senior Drinking Water Inspector III, per. comm.). 
Final draft of paper accepted for publication in the Journal 'Water Policy'. Actual journal publication should be referenced.

'There was a profound ignorance of how the EU worked both on a day to day basis, the Department (of the Environment) didn't understand the bargaining and trading that took place when agreements were being decided upon... with regard to the Directive, they didn't fully understand what they were getting into. To begin with the UK was very bad at negotiations, the UK approach tended to be issue based...they couldn't be seen to tie it in with other issues and bargain...other Member States, particularly France and Germany were playing a much broader game' (Senior Civil Servant III DoE [England/Wales], per. comm.).

Therefore, one can argue that the attention of civil servants in England/Wales to the negotiations surrounding the Directive was lacking because they were unaware of the EU policy making process. As mentioned previously, this has been found to be associated with problems of application relating to a misinterpretation of MAC values and the legal standing of the Directive. Also, as demonstrated by numerous annual reports on drinking water quality (see DWI, 1991-2003; EPA, 1991-2003), England/Wales and Ireland have been in continual breach of the standards set by the Directive for drinking water quality, in part as consequence of their misinterpretation of MAC values. However, it is notable that when senior civil servants and water industry personnel in England/Wales did increase the 'attention' they paid to issue of MAC values, particularly when the industry was being prepared for privatisation, it became apparent to them that their incorrect interpretation had major ramifications for future investment decisions within the water industry post-privatisation. With regard to the consequences of this increased attention, it is notable that during the first 
Final draft of paper accepted for publication in the Journal 'Water Policy'. Actual journal publication should be referenced.

Assessment Management Plan period (1989-1995) that followed water privatisation in England/Wales, upwards of $£ 6,000000000$ was invested in upgrading water treatment and distribution systems aimed at improving compliance with the quality standards of EU water directives, not least Directive 80/778/EEC (see Jenkins 2010a).

\section{The Directive and the allocation of duties and resources}

Effective policy design consists of a series of goals, instruments for achieving goals, a designation of bodies charged with delivery of goals, and an allocation of resources for necessary actions (Winter, 2003). With regard to the Directive, it is notable that it did not specify what bodies were to be charged with delivery of goals, or the allocation of resources necessary to ensure effective application (see CEC, 1980). In the context of the EU, this is delegated to Member States and, therefore, results in such policy decisions being taken at a national level. This response has accorded England/Wales and Ireland great flexibility in how they have chosen to apply the Directive, as an interviewee remarked:

'The freedom of the directive as the policy instrument was of tremendous importance to Member States, the freedom of process was very important as it enabled Member States to interpret and implement the Directive as they saw fit' (Senior Civil Servant II DoE [England/Wales], per. comm.).

However, and as highlighted earlier, this 'freedom of interpretation' is associated with problems of application, particularly with regard to correctly interpreting and fashioning an appropriate national response to the Directive. Indeed, previous research by the author has shown that when such 'freedom of interpretation' combines with issues of political 'priority' and 'ideology' at the national level, very different 
Final draft of paper accepted for publication in the Journal 'Water Policy'. Actual journal publication should be referenced.

organisational responses to the application of EU water directives can emerge which can lead to very different policy outcomes, such as the ability (or not) to meet the quality standards specified by directives (see Jenkins, 2010a and b).

\section{SUMMARY AND CONCLUSIONS}

This paper has sought to develop an understanding of how the policy development stage of the Drinking Water Directive (80/778/EEC) may have affected its application in England/Wales and Ireland. As a result, it is argued that some useful insights into how certain policy development issues can affect policy application have been gained, namely: conflicting interests, invalid causal theories, political symbolism, lack attention by policy-makers, and the allocation of duties and resources.

From the perspective of England/Wales and Ireland, it was found that the development of the Directive was the subject of conflicting Member State interests that in part stemmed from the implications of certain water quality standards being adopted. From a comparative perspective, it was found that political symbolism and the level of attention accorded the policy negotiations of the Directive may have had quite differing rationales or factors behind them. However, regardless of any such differences, a lack of attention and political symbolism were found to be associated with problems of application in both contexts. It was also found, again due to differing reasons, that senior civil servants in England/Wales and Ireland were not able to dedicate as much attention as they may have otherwise wanted to to the development of the Directive. Finally, it was observed that the Directive's vagueness with regard to what organisations should be responsible for during the Directive's 
Final draft of paper accepted for publication in the Journal 'Water Policy'. Actual journal publication should be referenced.

application in Member States, and how they should be funded, was associated with delays and problems of application.

Although this paper has sought to address the lack of knowledge within the water industry of how policy development can be construed as shaping the development and eventual application of drinking water policy, the discussion contained in this paper should not be taken as implying that considerable lessons have not been learned by all parties involved in the development and application of EU water policy. If reference is not made to this fact, this paper could be taken as implying wrongly that the policy development and application issues explored in this paper are still prevalent, particularly with regard to the preparations made for the current Drinking Water Directive (98/883/EC). Indeed, in relation to the development of Directive 98/883/EC, it is notable that civil servants and the water industry in England/Wales, and within Eureau, have sought to work far more closely with the European Commission, European Parliament and other Member State governments to try to ensure that many of the policy development deficiencies highlighted in this paper are addressed. For example, joint conferences between Eureau and the European Commission can be viewed as indicating a more attentive approach to policy development that is based on more informed judgements about the costs and practicalities of compliance.

Despite this paper serving to generate an increased awareness of the policy development issues that can affect the application of water policy, a greater recognition of the political and/or economic interests of Member States, and the politically symbolic acts they result in, should be more openly recognised so as to facilitate the development of effective application responses that limit the potential downsides of political symbolism. Acknowledgement of this issue is arguably of most 
Final draft of paper accepted for publication in the Journal 'Water Policy'. Actual journal publication should be referenced.

relevance to newer Member States of the EU who are far less experienced in dealing with and appreciating the consequences of their policy actions at the European level. So, given that this study indicates that the time policy-makers were able to dedicate to the development of Directive 80/778/EEC was limited due to the size of the Member States' bureaucracy and experience levels, it might be pertinent to suggest that the European Commission, in addition to targeting cohesion and structural funding at newer Members States, should also be seeking to identify ways in way it can boost the bureaucratic capabilities of newer Member States. The outcomes of any such policy response would then allow newer Member States to learn more effectively from the past mistakes of its older members and, in doing so, improve the application of European water policy and of other policy in general.

\section{REFERENCES}

Breach, R. A. (1989). The EC Directive on Drinking Water (EEC 80/778). Journal of the Institute of Water and Environmental Management 3, 323-327.

Carter, N. (2007). The Politics of the Environment. Cambridge University Press, Cambridge.

Cini, M. (2007). European Union Politics. Oxford University Press, Oxford.

Collins, K., (1988). Report on the Implementation of European Community Legislation Relating to Water (European Parliament Session Document A2 0298/80). European Parliament, Brussels.

Commission of the European Commission (1975). Proposal for a Council Directive relating to the quality of water for human consumption. Com (75) 394 final, 22 July. EC, Brussels. 
Final draft of paper accepted for publication in the Journal 'Water Policy'. Actual journal publication should be referenced.

Commission of the European Commision (1980). Council Directive 80/778/EEC relating to the quality of water intended for human consumption. Official Journal of the European Communities (L229), 30 August. EC, Brussels.

Department of the Environment (1982). Circular 20/82. EC Directive relating to the quality of water intended for human consumption (80/778/EEC). DoE, London.

Department of the Environment and Local Government (1988). Circular L6/88. European Communities (Quality of water intended for human consumption) Regulations. DOELG, Dublin.

Department of the Environment and Local Government (1983). Circular L6/83. EC Directive 80/778/EEC relating to the quality of water intended for human consumption. DOELG, Dublin.

Drinking Water Inspectorate (1990, 1991, 1992, 1993, 1994, 1995, 1996, 1997, 1998, 1999, 2000, 2001, 2002, 2003). Drinking Water: A Report by the Chief Inspector, Drinking Water Inspectorate. HMSO, London.

Economic and Social Committee (1976). Report of the Section for Protection of the Environment, Public Health and Consumer Affairs, on the Proposal for a Council Directive relating to the quality of water for human consumption. EC, Brussels.

Environment Commission (1998). Synthesis Report on the quality of drinking water in the Member States of the European Union in the period 1993-1995. Environment Commission, Brussels.

Environmental Protection Agency (1990, 1991, 1992, 1993, 1994, 1995, 1996, 1997, 1998, 1999, 2000, 2001, 2002, 2003). The quality of drinking water in Ireland. Environmental Protection Agency, Co. Wexford. 
Final draft of paper accepted for publication in the Journal 'Water Policy'. Actual journal publication should be referenced.

Foundation for Water Research (1998). Drinking water quality in the Netherlands: A report for the Drinking Water Inspectorate (DWI0402). FWR, Marlow.

Friends of the Earth (1991). Water Quality: The role of European Community Laws. Friends of the Earth, London.

Haigh, N. (1998). Manual of Environmental Policy: The EC and Britain. Longman, Harlow.

Horth, H., Gendebien, A., Casillas, J., Farmer, A. \& Crathorne, B. (1998). Investigation of Drinking Water Quality Enforcement Procedures in Member States of the European Union: Final Report to the Department of the Environment, Transport and the Regions. WRc plc, Marlow.

House of Lords Select Committee on the European Communities (1992). Ninth Report 1991-1992: Implementation and Enforcement of Environmental Legislation. HMSO, London.

House of Lords Select Committee on the European Communities (1976). Nineteenth Report 1975-1976. HMSO, London.

Jenkins, J.O. (2010a). the impact of politics on the application of the Drinking Water Directive (80/778/EEC). Water and Environment Journal 24 (3): 228-236.

Jenkins, J. O. (2010b). Organisational arrangements and drinking water quality. Water Science and Technology: Water Supply 10 (2): 227-241.

Jordan, A., Ward, N. \& Buller, H. (1998). Surf, sea, sand...and sewage: implementing European bathing water policy in the United Kingdom and France. Environment and Planning A 30, 1389-1408.

Knoepful, P., Lundqvist, L., Prud'homme, R. \& Wagner, P. (1987). Comparing environmental policies: different styles, similar content. In: Dierkes, M., Weiler, 
Final draft of paper accepted for publication in the Journal 'Water Policy'. Actual journal publication should be referenced.

H., \& Antal, A. (eds), Comparative Policy Research: Learning from Experience. Gower Publishing Company, Aldershot.

Maloney, W. \& Richardson, J. (1995). Managing Policy Change in Britain: The Politics of Water. Edinburgh University Press, Edinburgh.

McCormick, J. (2001). Environmental Policy in the European Union. Palgrave, Basingstoke.

National Society for Clean Air and Environmental Protection (2000). Pollution Handbook 2000. NSCA, Brighton.

Organisation for Economic Co-operation and Development (1994). Environmental Performance Reviews - United Kingdom. OECD, Paris.

Organisation for Economic Co-operation and Development (2000). Environmental Performance Reviews - Ireland. OECD, Paris.

Summerton, N. (1998). The British Way in Water. Water Policy 1, 45-65.

The Times (1993). Water watchdog urges challenge to EC clean-up. The Times, London, 14/07/1993.

The Times (1993). EC attacked over rising water costs. The Times, London, 30/03/1993.

The Times (1992). Paying for purity. The Times, London, 14/08/1992.

Vogel, D. (1987). The comparative study of environmental policy: a review of the literature. In: Dierkes, M., Weiler, H., \& Antal, A. (eds), Comparative Policy Research: Learning from Experience. Gower Publishing Company, Aldershot.

Water Authorities Association (1987). The Water Briefing: Drinking Water Quality The Facts. WAA, London.

Winter, S. (2003). Implementation. In: Peters, B. \& Pierre, J. (eds) Handbook of Public Administration. Sage Publications, London. 
Final draft of paper accepted for publication in the Journal 'Water Policy'. Actual journal publication should be referenced.

Received 3 March 2010; accepted in revised form 4 July 2011. Available online 